\title{
Protection of Susceptible Potato Cultivars Against Late Blight in Mixtures Increases with Decreasing Disease Pressure
}

\author{
F. Pilet, G. Chacón, G. A. Forbes, and D. Andrivon
}

First and fourth authors: INRA-UMR BiO3P, Domaine de la Motte, BP 35327, F-35653 Le Rheu Cedex, France; and second and third authors: Centro Internacional de la Papa, Casilla 17-21-1977, Quito, Ecuador.

Current address of first author: CIRAD-CP, OPRI, P.O. Box 245, Sekondi, Ghana.

Current address of third author: CIP, Apartado 1558, Lima 12, Peru.

Accepted for publication 9 March 2006.

\begin{abstract}
Pilet, F., Chacón, G., Forbes, G. A., and Andrivon, D. 2006. Protection of susceptible potato cultivars against late blight in mixtures increases with decreasing disease pressure. Phytopathology 96:777-783.

Cultivar mixtures can reduce potato late blight severity on susceptible cultivars. While alternating rows of susceptible and resistant cultivars would be more acceptable than random mixtures for commercial use, they increase the genotype unit area, which is an unfavorable factor for mixture efficiency, and have been minimally efficient when disease pressure is high. The effects of disease pressure on the performance of alternating rows of cultivars possessing various types and levels of resistance were investigated in 2000 and 2001 near Quito, Ecuador, where natural pressure of late blight is high. The experiments included the highly susceptible cvs. Cecilia in 2000 and LBr37 in 2001, as well as C114 (moderately resistant) and PAN (highly resistant), planted as pure stands and as the three possible two-way combinations. Different disease pres-
\end{abstract}

ABSTRACT sures were obtained with three spraying schedules of a contact fungicide: nontreated, one spray every second week, and one spray weekly. The area under the disease progress curve (AUDPC) on the susceptible cultivar was 0 to $20 \%$ less in mixed than in pure plots when no fungicide was applied, 13 to $26 \%$ less with a biweekly application of fungicide, and 32 to $53 \%$ less with a weekly application. These values are comparable to those obtained in previous experiments in smaller plots with designs maximizing the distance between susceptible plants. No significant differences in mixture performance were observed according to the resistant cultivar included. Effects on yield were minimal, because of the impact of factors other than late blight. Disease pressure therefore appears as a major factor conditioning the efficiency of potato cultivar mixtures against late blight.

Additional keywords: Phytophthora infestans.
Mixing host plant species or cultivars can slow down the epidemic development of many airborne pathogens, such as Puccinia triticina (4,15), Blumeria graminis (4,29), Uromyces phaseoli, Puccinia sorghi (20), Magnaporthe grisea (30), or Xanthomonas axonopodis pv. vesicatoria (12). Mixtures of resistant and susceptible cultivars impair epidemic spread in three different ways: first, the resistant component in the mixture constitutes a physical barrier to inoculum dispersal between susceptible plants; second, it reduces pathogen multiplication and therefore the quantity of inoculum available in the plot; and third, the challenge of resistant plants by avirulent pathogen genotypes can trigger induced resistance against further infection by virulent pathogen genotypes $(5,29)$. Therefore, the greatest effect of mixtures is expected for host-pathogen systems which favor alloinfection over autoinfection (i.e., small-leafed, small host plants; shallow pathogen dispersal gradients; small, nonexpanding lesions), have a strong epidemic potential (i.e., short pathogen generation times), and pathogen populations with strong specialization to specific host cultivars (5).

Although the potato-Phytophthora infestans pathosystem does not fulfill all these criteria, cultivar mixtures have been shown to decrease late blight spread and final severity in France (1), Oregon (6), and Ecuador (7). In the experiments of Garrett and Mundt (6) and Garrett et al. (7), the position of the different cultivars was either randomized or determined to maximize the

Corresponding author: D. Andrivon; E-mail address: Didier.Andrivon@ rennes.inra.fr

DOI: $10.1094 /$ PHYTO-96-0777

(C) 2006 The American Phytopathological Society distance between individuals of the same genotype. Such designs are adequate to maximize disease reduction by mixtures, but would be unsuitable for most commercial uses, for at least two reasons. First, planting large fields according to such designs might prove complicated and/or time-consuming. Second, these designs imply that the crop is harvested as a mixture of tubers. While such mixtures might be acceptable for the starch potato industry (provided all cultivars in the mixture have similar starch contents and technological properties), they are incompatible with the current requirement for the ware and seed growers to market pure varieties. Growing cultivars as alternating rows responds in part to this problem, and resulted in significant reduction of late blight severity in small scale experiments in France (1). However, no statistically significant effects of cultivar associations in rows were observed in further experiments done in France in 1999 to 2002 (25), using susceptible, partially resistant, and totally resistant cultivars. Compared with random mixtures, alternating rows leads to an increase in the genotype unit area (GUA), defined as the area occupied by an independent unit of host tissue of the same genotype (19). A higher GUA leads to a higher proportion of secondary inoculum infecting the same host genotype, and therefore to a lower frequency of pathogen genotypes infecting different cultivars during the course of the epidemic. By favoring adaptation of each pathogen genotype to one of the cultivars, increasing GUA through higher aggregation of host genotypes usually decreases the disease-controlling effect of host diversity $(12,18,20)$. This hypothesis is consistent with results from recent field studies, showing that intrarow mixtures were more efficient than interrow mixtures to reduce sorghum anthracnose development (22), and that random mixtures provided both better disease 
control of yellow rust on wheat and better yield than did alternating strips or alternating hills (18). Selection for complex races of Erysiphe graminis f. sp. hordei was less intense in row mixtures of spring barley than in random mixtures (11), which is also consistent with the hypothesis that random mixtures work (at least in part) by causing pathogen genotypes to change host cultivars more frequently in polycyclic epidemics, therefore favoring local maladaptation between host and pathogen.

The climatic conditions observed from 1999 to 2002 in our trial sites in France were very favorable to late blight, leading to a high disease pressure (D. Andrivon and F. Pilet, unpublished data). Late blight disease pressure can, however, be controlled by fungicide applications. Fungicides may affect the disease suppressing efficacy of host mixtures in at least two ways-by reducing disease pressure and by increasing the number of pathogen cycles during the epidemic. Indeed, if fungicide applications slow down epidemics that would have led to the rapid destruction of plants, they will allow the epidemic to extend over a larger number of pathogen generations, which is expected to increase the effects of host diversity $(6,7,14)$. Garrett et al. (7) showed a greater host diversity effect in plots that received fungicide applications than in nontreated plots, and concluded that the combination of host diversity and fungicides was more promising than host diversity alone.

The objective of this study was thus to test the hypothesis that late blight control in alternating rows of potato cultivars with different levels of resistance depends on disease pressure (considered here as the resulting effect of available infectious inoculum in given environmental conditions). From an epidemiological point of view, the underlying objective was to complement the report of Garrett et al. (7) by assessing the effect of increased GUA and of cultivar resistance levels on mixture performance, and confront observations to theoretical predictions. A high natural pressure of late blight was modulated through different fungicide spraying schedules. The experiments were thus carried out in 2000 and 2001 in the highlands of Ecuador, where natural disease pressure is consistently high $(9,23)$ and where the combination of host diversity and fungicides had been previously investigated (7), although not in alternating rows.

\section{MATERIALS AND METHODS}

Experimental design. The potato cultivars used in this study included a highly susceptible clone (Cecilia [Cec] in 2000 and LBr37 in 2001), a moderately resistant clone (C114), and a resistant clone (PAN). C114 and PAN were derived from the International Potato Center (CIP, Peru) population A, and may have $R$ genes that match avirulence genes in the Ecuadorian population of $P$. infestans; neither cultivar has been grown extensively in Ecuador. We assume avirulence to Cecilia and LBr37 to be nonexistent or rare in the pathogen population. Cecilia is widely grown in Ecuador and is known for its high susceptibility to $P$. infestans. $\mathrm{LBr} 37$ is an experimental line that has always reacted as a susceptible genotype at Santa Catalina.

Plots were arranged in a randomized complete block design with two blocks. Each block contained 18 plots, corresponding to all combinations of six planting patterns (each cultivar in a pure stand and the three two-way combinations of the three cultivars in alternating rows) with three fungicide spraying schedules (nontreated, one spray every second week, or one spray weekly) of the contact fungicide Dithane (mancozeb; 1,600 g a.i. ha ${ }^{-1}$ ). Each plot consisted of eight rows, of 10 plants each. In the 2000 experiment, rows were $1.10 \mathrm{~m}$ apart, versus $0.8 \mathrm{~m}$ in the 2001 experiment. In both years, the distance between plants within rows was $0.4 \mathrm{~m}$. The potato plots were planted in a checkerboard pattern with buffer plots sown with oats (Avena sativa).

All experiments were carried out at the Estación Santa Catalina of CIP near Quito, Ecuador $\left(0^{\circ} 22^{\prime} \mathrm{S}, 78^{\circ} 33^{\prime} \mathrm{W}\right)$. Plots were planted on 22 December 1999 and on 4 December 2000, respectively, for the 2000 and 2001 experiments.

Disease assessments and statistical analyses. Disease severity was scored weekly on four randomly chosen plants of each of the six inner rows in each plot, as the percentage of foliage tissue blighted. Disease assessments started with observation of the first symptoms (30 January 2000 and 17 January 2001, respectively), and continued until the nontreated susceptible plot was entirely destroyed (nine scoring dates in 2000 and eight scoring dates in 2001). Disease progress curves were fitted to the logistic and Gompertz models through linear regression over time of disease severity $(s)$ transformed as $\ln [s /(100-s)]$ and $-\operatorname{Pn}[-\operatorname{Pn}(s)]$, respectively. These models were chosen because they fit numerous plant disease progress curves (2) and had proved adequate to describe late blight progress in cultivar associations (1). Both models fitted the data quite closely; however, the logistic model was slightly better based on the analysis of variance (ANOVA) parameters of the regressions. Furthermore, the area under the disease progress curve (AUDPC) was calculated for each year $\times$ cultivar $\times$ plot combination using the trapezoidal integration method (2) and analyzed by ANOVA with blocks as replicates.

The weight of tubers per row were averaged for each cultivar and plot and analyzed by ANOVA separately for each cultivar, with blocks as replicates. No comparison of total yield per plot was attempted because of the large differences in yield potential between cultivars.

Relative mixture responses (RMR) for AUDPC were calculated for each cultivar in each plot as the AUDPC of a cultivar in mixture divided by the AUDPC of this cultivar in the pure plot. RMR values were also calculated for yield, in a similar way. RMR values were analyzed by ANOVA to test for differences between mixtures, as well as by linear regression on fungicide sprays per fortnight (i.e., 0 for nontreated plots, 1 for biweekly sprays, and 2 for weekly sprays) to assess the impact of disease pressure on mixture performance. All ANOVA calculations were performed with the PROC GLM module of the SAS statistical software. Regression analyses were performed using the PROC REG module of the same software.

\section{RESULTS}

Late blight resistance of the potato genotypes. Cecilia and LBr37 were always the most susceptible genotypes, as shown by the late blight progress curves in nontreated plots (Fig. 1). C114 was more susceptible than PAN. The apparent infection rates were not significantly different in nontreated LBr37 in 2001 and in nontreated Cecilia in 2000 (Table 1), indicating that the two cultivars were of similar susceptibility. Overall, the disease progressed faster in 2000 than in 2001, as shown by the higher apparent infection rates in 2000 in pure, nontreated plots of C114 and PAN (Table 1).

Disease pressure and mixture performance. Increasing the frequency of fungicide sprays reduced AUDPCs (Fig. 2), mainly through a reduction of apparent infection rates (Table 1). Fungicide sprays also consistently increased the benefit of associations for limiting AUDPCs on the susceptible cultivar (Fig. 3). For instance, the AUDPCs on Cecilia (2000 trial) was 5 to $16 \%$ less in mixed plots than in pure plots when no fungicide was applied, 25 to $26 \%$ less with a biweekly application of fungicide, and 49 to $53 \%$ less with a weekly application, depending on whether the mixture was with $\mathrm{C} 114$ or PAN. This increase in mixture effect was significant, as shown by the significant negative correlation between RMR for AUDPC and the number of fungicide applications per fortnight in Cecilia $(r=-0.72, P<0.01$; Table 2). In 2001 , a disease reduction in susceptible cultivars used in mixtures over the same in pure plots, increasing with increasing fungicide application frequency, was also observed, although none of the differences observed proved significant at the 5\% threshold (Fig. 
2). For instance, in nontreated plots, AUDPC was $20 \%$ lower on the susceptible cv. LBr37 associated with PAN, but was equivalent to the pure plot in the $\mathrm{LBr} 37 / \mathrm{C} 114$ association. A benefit of 13 to $32 \%$ for mixed versus pure plots was observed in the fungicide-sprayed crops (Fig. 3).

AUDPCs were slightly higher on the two resistant cultivars in mixed plots than in pure plots, irrespective of fungicide spraying regimes (Figs. 2 and 3). However, this increase was never statistically significant (Student Newman and Keuls test, $P>0.05$ ). Mixing tended to reduce logistic apparent infection rates in both the susceptible and partially resistant cultivars (Table 1).

Mixture performance on yield. Slight yield increases were observed for the susceptible cultivar in most mixed plots over pure plots (Fig. 3A and B), as shown by the marginally significant number of RMR values exceeding 1 ( 9 plots out of $12 ; P=0.073$ in a one-sided Fisher sign test of the differences between RMR values and 1 [10]). However, the increases were limited, and the extra yield benefit due to mixtures was usually not directly related to fungicide spraying frequency (Fig. 3). The only significant cor- relation between RMR for yield and fungicide sprays per fortnight was observed for Cecilia in $2000(r=-0.71, P=0.03)$. Yields of resistant cultivars did not show any consistent trend in mixed over pure plots, irrespective of fungicide sprays (Table 2; Fig. 3).

\section{DISCUSSION}

Disease pressure appears to be an important factor conditioning the performance of potato cultivar mixtures in late blight control, as shown by the increase in mixture effect on the susceptible genotype with increasing fungicide sprays. This observation is in line with previous results obtained in Quito (7) and with observations in other pathosystems (21).

Interestingly, a consistent, although limited reduction of disease on the more susceptible genotypes was observed in the nontreated mixed plots, confirming previous observations $(1,6,7)$. To be worthwhile in practice, mixing genotypes with different levels of race-non-specific resistance should result in a net gain, i.e., induce a greater reduction of disease on the more susceptible

\section{0}

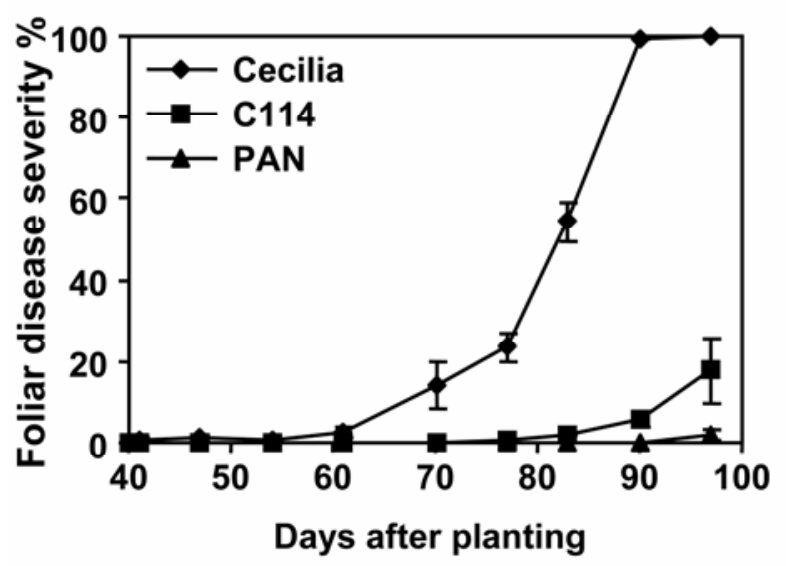

\section{1}

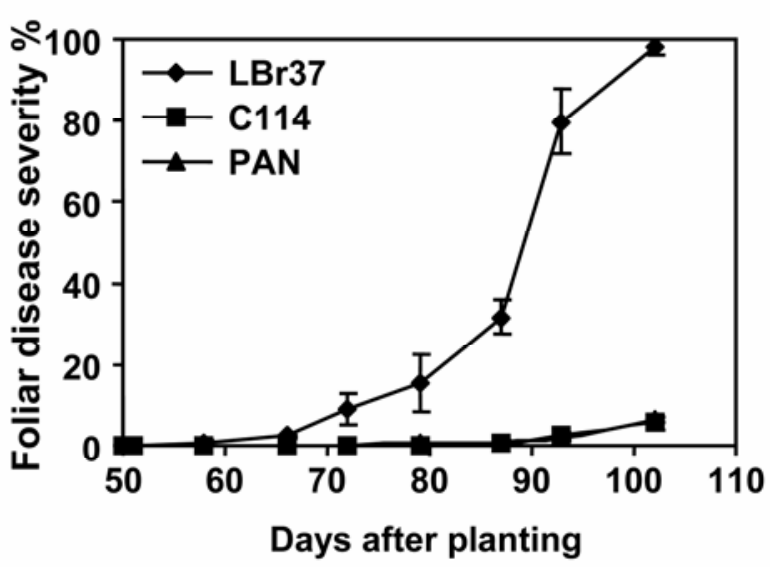

Fig. 1. Disease progress curves for late blight in nontreated pure plots of potato cvs. Cecilia/LBr37 (susceptible), C114 (moderately resistant), and PAN (highly resistant) in 2000 and 2001.

TABLE 1. Logistic apparent infection rates for late blight progress in pure and mixed potato plots sprayed with mancozeb at different regimes in Quito, Ecuador, in 2000 and $2001^{\mathrm{a}}$

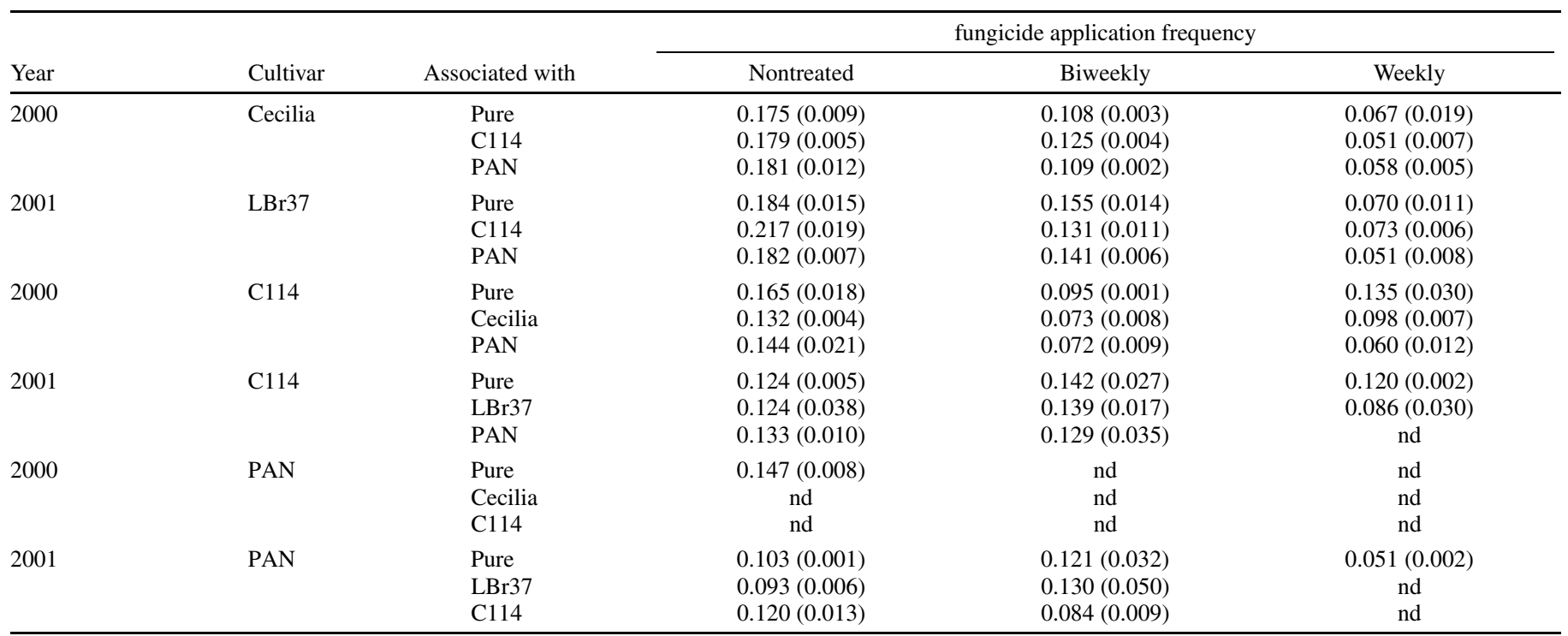

a Indicated are mean and standard deviations (in parentheses) from two replicate plots per treatment. Associations consisted of alternating rows of the cultivars indicated. nd indicates "could not be determined" (too few scoring dates available when disease was present; logistic regression not significant). 
genotype than the disease increase on the more resistant genotype. However, this balance cannot be properly assessed using RMRs. In fact, while RMRs for AUDPC increased up to 13 to $14 \%$ on the partially resistant genotypes C114 and PAN, these high RMR values (which could be interpreted as a large detrimental effect of mixing on partially resistant genotypes) corresponded to small increases in the absolute values of the very low AUDPC values recorded in those genotypes. These increases are not statistically significant and should therefore not be considered when assessing mixture performance.
While stronger disease reductions on the susceptible cultivar in mixed plots with increasing fungicide sprays was consistently observed over the 2 years and the different mixture combinations experimented, the magnitude of this increase differed between the 2 years. Part of this could be due to the change in susceptible cultivar between the 2 years, as well as to differences in disease pressure. The comparison of logistic apparent infection rates in pure, nontreated plots of $\mathrm{C} 114$ indicates that the disease pressure was higher in 2000 than in 2001. Despite this, disease progress was generally faster in plots mixed with LBr37 (2001) than in
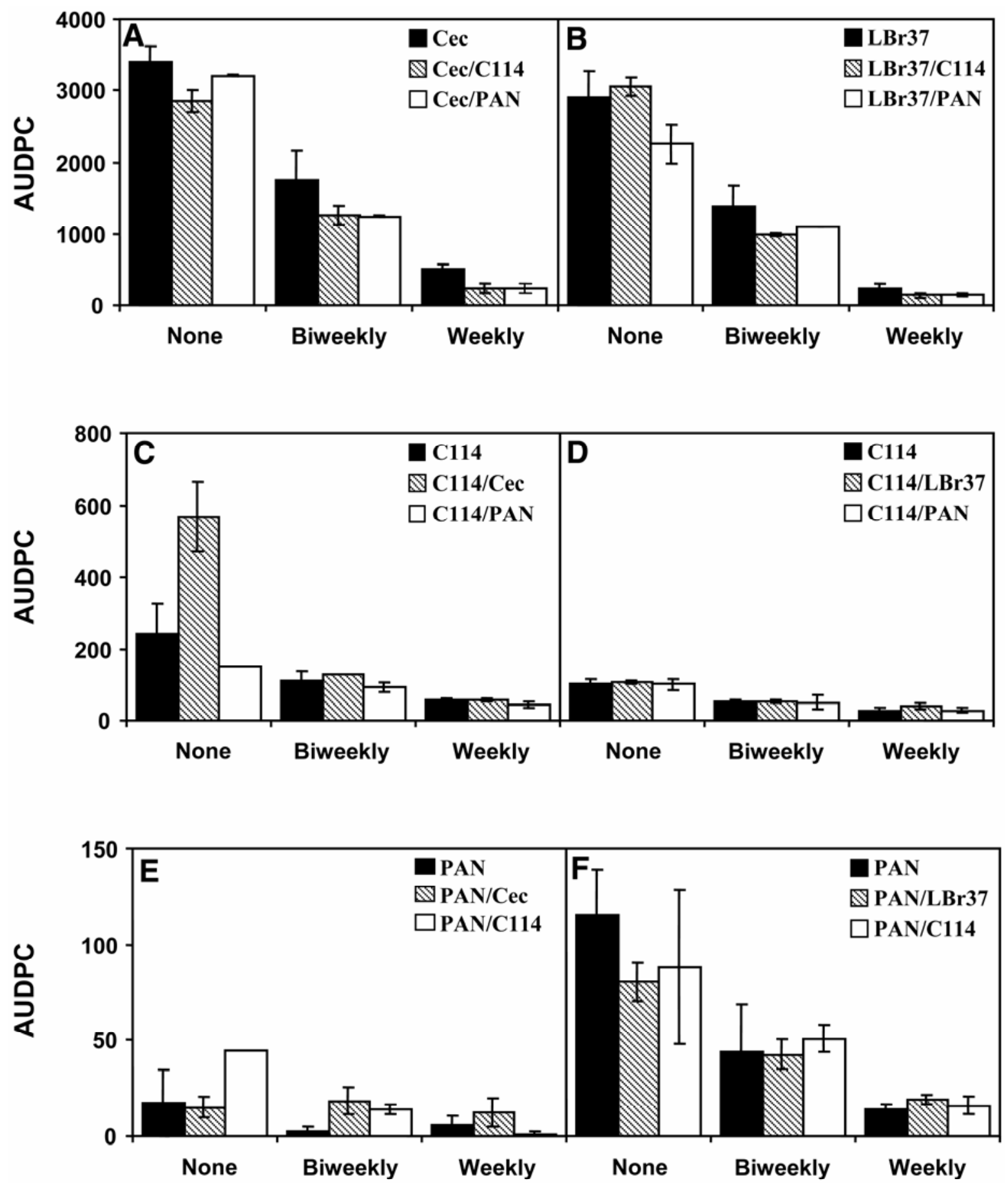

Fungicide applications

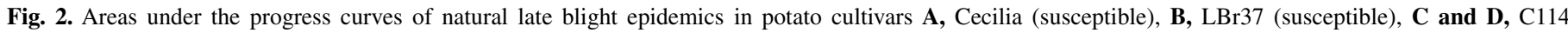

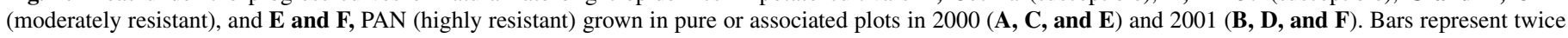
the standard error of the means. 
plots mixed with Cecilia (2000), and slightly faster in pure, nontreated plots of $\mathrm{LBr} 37$ than in pure, nontreated plots of Cecilia. This suggests that $\mathrm{LBr} 37$ is more susceptible to late blight than Cecilia is. The two cultivars also differ in plant and canopy architecture, which can also have a large impact on mixture performance and inoculum spread (31); LBr37 is a tall, erect cultivar, whereas Cecilia is a shorter, decumbent cultivar. The lesser bene- fit on disease reduction in treated plots in 2001 might therefore be a consequence of a higher disease pressure in the LBr37containing plots than in the Cecilia-containing plots.

Epidemics on PAN and C114 started later than on Cecilia and LBr37 in both years, which probably resulted from a high frequency of avirulence in the pathogen to $\mathrm{R}$ genes in these resistant cultivars. The race-specific mode of action of such genes, which
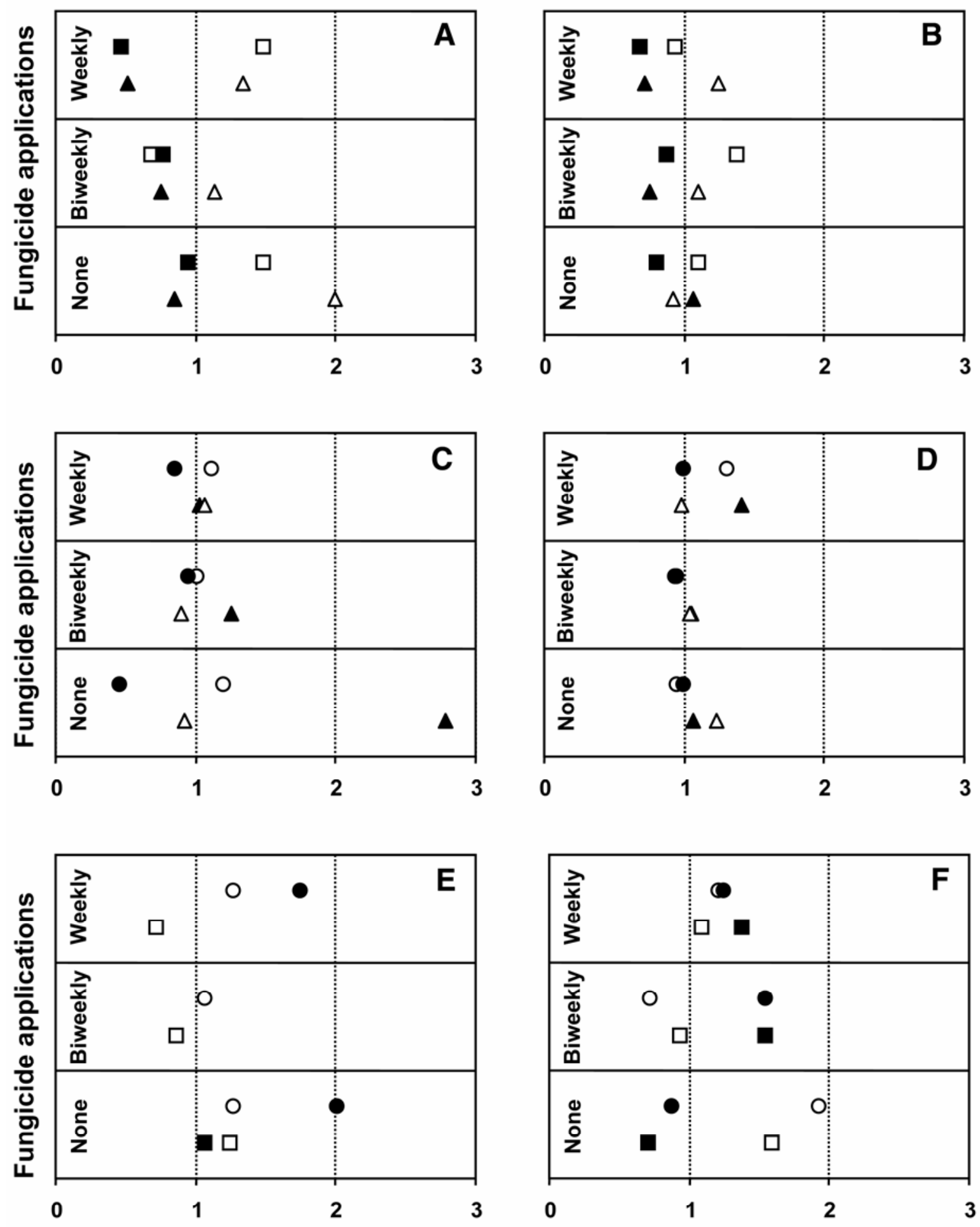

Relative mixture response (RMR)

Fig. 3. Relative mixture response for areas under the progress curves (RMR AUDPCs) (filled symbols) and for yield (RMR yield) (open symbols) calculated for the susceptible (S) cultivars A, Cecilia and $\mathbf{B}, \mathrm{LBr} 37, \mathbf{C}$ and $\mathbf{D}$, the moderately resistant cv. C114, and $\mathbf{E}$ and $\mathbf{F}$, the highly resistant cv. PAN. Graphs $\mathbf{A}, \mathbf{C}$ and $\mathbf{E}$, 2000 trial; graphs B, D and F, 2001 trial. Symbols: triangle = S/C114; square = S/PAN; and circle = PAN/C114. Positive mixture effects are indicated by RMR values below 1 for AUDPCs and above 1 for yield. 
adversely affects their durability (28), is most often used in experimental and commercial mixtures, as it magnifies mixture effects (4,5). Although C114 was more susceptible than PAN (at least in 2000), there was no significant difference in performance of mixtures according to the resistant cultivar included. Previous experiments with late blight used cultivars with either partial resistance (1) or with $\mathrm{R}$ genes with incomplete effectiveness (7). Because these experiments were not identical in layout and were not performed simultaneously, they cannot be directly compared to ascertain the respective effects of resistance performance and spatial deployments patterns on mixture effects. This was attempted in another set of experiments, to be reported elsewhere.

Lower epidemic rates and/or changes in dispersal gradients are two potential mechanisms explaining the increase of mixture effect with decreasing disease pressure. Indeed, the disease reduction in mixtures is greatest when the number of pathogen multiplication cycles increases $(5,14)$ and with pathogens dispersed over long distances with a shallow gradient (5). The fungicide sprays employed to decrease disease pressure also decreased the rate of disease progress in all plots, as shown by the significant fungicide effects on AUDPCs. By significantly slowing down epidemics that led to the rapid destruction of susceptible plants in the nontreated plots, the reduction in disease resulting from the fungicide sprays allowed the epidemic to carry over for a larger number of pathogen generations, and favored the effects of host diversity.

Besides limiting disease pressure, fungicide sprays probably also alter the shape of dispersal gradients, by reducing autoinfection and favoring long-distance dispersal. Literature is limited about both the dissemination of $P$. infestans at very short distances and the distribution of the sporangia produced by a plant into auto- and alloinoculum. Sporangia can be dispersed by both wind and splashing (8). Dispersal gradients of $P$. infestans tend to be relatively shallow $(6,24)$; however, the level of autoinfection is considered high in the potato late blight pathosystem (26). Minogue and Fry $(16,17)$ showed that the dispersal gradient becomes steeper as the sporulation rate or infectious period increases, and that both rate-limiting resistance and fungicide treatments cause gradients to become significantly flatter. This is particularly true for contact fungicides, like mancozeb used in our experiments, which essentially affects spore germination (27). Such a decrease of autoinfection in sprayed crops therefore favors the reduction of the disease by genotype mixtures.

When autoinfection is high, the disease reduction by mixtures should be low, and little influenced by a high GUA. The relatively high mixture effects observed in our experiments, comparable to those recorded by Garrett et al. (7) in spite of a higher GUA, could be due to the fact that our plots were twice the size of those

TABLE 2. Regression analysis of relative mixture responses (RMR) for late blight control in plots including a susceptible cultivar (Cecilia or LBr37) and one of two resistant potato cultivars (C114 and PAN) grown in alternating rows in Quito, Ecuador ${ }^{\mathrm{a}}$

\begin{tabular}{llcccc}
\hline Variables & Cultivar & Year & $\begin{array}{c}\text { Regression } \\
\text { coefficient }\end{array}$ & $\begin{array}{c}\text { Correlation } \\
\text { coefficient }(r)\end{array}$ & $P$ \\
\hline RMR AUDPC & & & & & \\
& Cecilia & 2000 & -0.189 & -0.709 & 0.032 \\
& LBr37 & 2001 & -0.054 & -0.249 & 0.433 \\
& C114 & 2000 & -0.088 & -0.523 & 0.147 \\
& C114 & 2001 & 0.036 & 0.089 & 0.783 \\
RMR yield & & & & & \\
& Cecilia & 2000 & -0.100 & -0.725 & 0.008 \\
& LBr37 & 2001 & -0.116 & -0.363 & 0.245 \\
& C114 & 2000 & 0.592 & 0.676 & 0.022 \\
& C114 & 2001 & 0.230 & 0.512 & 0.089 \\
& PAN & 2000 & 0.991 & 0.599 & 0.051 \\
& PAN & 2001 & 0.264 & 0.317 & 0.316 \\
\hline
\end{tabular}

${ }^{\mathrm{a}} \mathrm{RMR}$ for yield or for areas under the disease progress curve (AUDPC) were regressed on the number of fungicide applications per fortnight to the plots. of Garrett et al. (7). Besides reducing interplot interference, the larger plot size also probably allowed the epidemics to carry on for longer periods, and thus favored the manifestation of disease reduction benefits by mixtures, particularly in the slower epidemics (fungicide-sprayed plots).

While fungicide sprays consistently increased mixture effects, this increase was probably not maximal because of the type of fungicides used. Mancozeb was selected for this trial to decrease disease pressure, i.e., the quantity of potentially infectious sporangia. Although mancozeb can somewhat reduce mycelium growth in axenic in vitro tests (3), it has no curative effect in the field, and therefore does not limit lesion growth. Lesion growth is known to adversely affect the efficacy of mixtures for disease reduction (13). Therefore, the use of translaminar (such as cymoxanil), locally systemic (such as dimethomorph), or fully systemic fungicides (such as phenylamides) would probably further increase the performance of sprayed mixtures, as such fungicides would both decrease disease pressure and limit the extension of existing lesions.

Overall, cultivar mixtures had a limited, although consistent effect on disease control. Their low efficacy in untreated plots increased with fungicide applications. The practical value of mixing, at least in environments highly conducive to late blight, is therefore only as a component of an integrated control strategy, combining the disease reduction possibilities offered by both cultivar mixture and fungicides. This conclusion concurs with that of Garrett et al. (7). It should however be noted that in environments with low disease pressure, mixing alone provides up to $50 \%$ disease reduction, as was shown in France in 1993 (1). We therefore think that the use of mixtures against late blight should be tailored to the conduciveness to blight of the location and to the availability of other, more efficient control possibilities (fungicides, resistant cultivars, etc.). It is interesting to note that mixtures essentially increased the protection of susceptible cultivars. In potato, but also in many other crops, these susceptible cultivars are often sought by growers because of their high utilization value (30). A complete assessment of the value of mixtures can thus only be made on the long run. It should take into account both the direct effect on disease but also the economic returns associated with it $(29,30)$, which cannot be properly assessed in an experimental setting such as the one used here.

\section{ACKNOWLEDGMENTS}

Financial support from the Direction for International Relationships of INRA to F. Pilet for the experiments in Ecuador is gratefully acknowledged. F. Pilet was supported by a Ph.D. grant from the French Ministry for Higher Education and Research.

\section{LITERATURE CITED}

1. Andrivon, D., Lucas, J. M., and Ellissèche, D. 2003. Development of natural late blight epidemics in pure and mixed plots of potato cultivars with different levels of partial resistance. Plant Pathol. 52:586594.

2. Campbell, C. L., and Madden, L. V. 1990. Introduction to Plant Disease Epidemiology. Wiley Interscience, New York.

3. Daayf, F., and Platt, H. W. 2002. Variability in responses of US-8 and US11 genotypes of potato and tomato isolates of Phytophthora infestans to commercial fungicides in vitro. Am. J. Potato Res. 79:433-441.

4. Finckh, M. R., Gacek, E. S., Goyeau, H., Lannou, C., Merz, U., Mundt, C. C., Munk, L., Nadziak, J., Newton, A. C., de Vallavieille-Pope, C., and Wolfe, M. S. 2000. Cereal variety and species mixtures in practice, with emphasis on disease resistance. Agronomie 20:813-837.

5. Garrett, K. A., and Mundt, C. C. 1999. Epidemiology in mixed host populations. Phytopathology 89:984-990.

6. Garrett, K. A., and Mundt, C. C. 2000. Host diversity can reduce potato late blight severity for focal and general patterns of primary disease. Phytopathology 90:1307-1312.

7. Garrett, K. A., Nelson, R. J., Mundt, C. C., Chacon, G., Jaramillo, R. E., and Forbes, G. A. 2001. The effects of host diversity and other manage- 
ment components on epidemics of potato late blight in the humid highland tropics. Phytopathology 91:993-1000.

8. Harrison, J. G. 1992. Effects of the aerial environment on late blight of potato foliage-A review. Plant Pathol. 41:384-416.

9. Hijmans, R. J., Forbes, G. A., and Walker, T. S. 2000. Estimating the global severity of potato late blight with GIS-linked disease forecast models. Plant Pathol. 49:697-705.

10. Hollander, M., and Wolfe, D. A. 1973. Nonparametric Statistical Methods. John Wiley \& Sons, New York.

11. Huang, R., Kranz, J., and Welz, H. G. 1994. Selection of pathotypes of Erysiphe graminis f. sp. hordei in pure and mixed stands of spring barley. Plant Pathol. 43:458-470.

12. Kousik, C. S., Sanders, D. C., and Ritchie, D. F. 1996. Mixed genotypes combined with copper sprays to manage bacterial spot of bell peppers. Phytopathology 86:502-508.

13. Lannou, C., de Vallavieille-Pope, C., Biass, C., and Goyeau, H. 1994. The efficacy of mixtures of susceptible and resistant hosts to two wheat rusts of different lesion size: Controlled condition experiments and computerized simulations. J. Phytopathol. 140:227-237.

14. Leonard, K. J. 1969. Selection in heterogeneous populations of Puccinia graminis f. sp. avenae. Phytopathology 59:1851-1857.

15. Mahmood, T., Marshall, D., and McDaniel, M. E. 1991. Effect of winter cultivar mixtures on leaf rust severity and grain yield. Phytopathology 81:470-474.

16. Minogue, K. P., and Fry, W. E. 1983. Models for the spread of disease: Model description. Phytopathology 73:1168-1173.

17. Minogue, K. P., and Fry, W. E. 1983. Models for the spread of plant disease: Some experimental results. Phytopathology 73:1173-1176.

18. Mundt, C. C., Brophy, L. S., and Kolar, S. C. 1996. Effect of genotype unit number and spatial arrangement on severity of yellow rust in wheat cultivar mixtures. Plant Pathol. 45:215-222.

19. Mundt, C. C., and Browning, J. A. 1985. Development of crown rust epidemics in genetically diverse oat populations: Effect of genotype unit area. Phytopathology 75:607-610.

20. Mundt, C. C., and Leonard, K. J. 1986. Effect of host genotype unit area on development of focal epidemics of bean rust and common maize rust in mixtures of resistant and susceptible plants. Phytopathology 76:895-900.

21. Newton, A. C., Guy, D. C., Nadziak, J., and Gacek, E. S. 2002. The effect of disease pressure, germplasm selection and environment on spring barley cultivar mixtures efficacy. Euphytica 125:325-335.

22. Ngugi, H. K., King, S. B., Holt, J., and Julian, A. M. 2001. Simultaneous temporal progress of sorghum anthracnose and leaf blight in crop mixtures with disparate patterns. Phytopathology 91:720-729.

23. Oyarzun, P. J., Pozo, A., Ordonez, M. E., Doucett, K., and Forbes, G. A. 1998. Host specificity of Phytophthora infestans on tomato and potato in Ecuador. Phytopathology 88:265-271.

24. Paysour, R. E., and Fry, W. E. 1983. Interplot interference: A model for planning field experiments with aerially disseminated pathogens. Phytopathology 73:1014-1020.

25. Pilet, F. 2003. Epidémiologie et biologie adaptative des populations de Phytophthora infestans dans des cultures pures et hétérogènes de variétés de pomme de terre. Ph.D. Thesis. ENSA, Rennes.

26. Robinson, R. A. 1976. Plant Pathosystems. Springer-Verlag, New York.

27. Schwinn, F. G., and Margot, P. 1991. Control with chemicals. Pages 225 261 in: Advances in Plant Pathology, vol. 7. Phytophthora infestans, the Cause of Late Blight of Potato. D. S. Ingram and P. H. Williams, eds. Academic Press, London, UK.

28. Wastie, R. L. 1991. Breeding for resistance. Pages 193-224 in: Advances in Plant Pathology, vol. 7. Phytophthora infestans, the Cause of Late Blight of Potato. D. S. Ingram and P. H. Williams, eds. Academic Press, London, UK.

29. Wolfe, M. S. 1985. The current status and prospects of multiline cultivars and variety mixtures for disease resistance. Annu. Rev. Phytopathol. 23:251-273

30. Zhu, Y., Chen, H., Fan, J. H., Wang, Y., Li, Y., Chen, J. B., Fan, J. X., Yang, S., Hu, L., Leung, H., Mow, T. W., Teng, P. S., Wang, Z., and Mundt, C. C. 2000. Genetic diversity and disease control in rice. Nature 406:718-722.

31. Zhu, Y., Fang, H., Wang, Y., Fan, J. X., Yang, S., Mew, T. W., and Mundt, C. C. 2005. Panicle blast and canopy moisture in rice cultivar mixtures. Phytopathology 95:433-438. 